\title{
REFERENCE VALUES OF SCHIRMER TEAR TEST IN SHEEP AND THE EFFECT OF SEASON ON THE TEST RESULTS
}

\author{
Anna Dedousi ${ }^{1}$, Maria A. Karatzia ${ }^{2}$ and Panagiotis D. Katsoulos ${ }^{3 *}$ \\ ${ }^{1}$ Veterinary Research Institute, Hellenic Agricultural Organization, Demeter, Thessaloniki, \\ Greece; ${ }^{2}$ Research Institute of Animal Science, Hellenic Agricultural Organization, \\ Demeter, Paralimni Giannitsa, Greece, ${ }^{3}$ Clinic of Farm Animals, School of Veterinary \\ Medicine, Aristotle University of Thessaloniki, St. Voutyra 11, 54627 Thessaloniki, \\ Greece
}

(Received 25 June 2019; accepted 3 September 2019)

\begin{abstract}
The aim of this study was to determine the reference range of Schirmer tear test (STT) values in sheep using Greek indigenous and mixed breeds and to investigate the potential effect of breed and season on these values. Ninety (30 Chios, 30 Florina and 30 Lacaune mixed breed) ewes aged 2 years or more were used for the study. The aqueous portion of the tear film was measured using Schirmer tear test (STT) commercial strips bilaterally by the same investigator with the animal in standing position. The average STT value recorded was $18.45 \pm$ $3.93 \mathrm{~mm} / \mathrm{min}$ and the range $10.8-26.2 \mathrm{~mm} / \mathrm{min}$. STT was significantly affected by the season and the recorded values were significantly higher in summer compared to winter. The breed had no significant effect on tear secretion. The results of the present study provide a reference range of STT values in sheep and indicate that tear secretion is significantly affected by the season.
\end{abstract}

Key words: Schirmer tear test, sheep, season, tear secretion

The tear film is considered to have a unique structure with functions of nourishing, lubricating and protecting the ocular surface, containing lipid, protein, and mucous components (Ohashi et al., 2006; Tiffany, 2008). The secretion of tears serves for cleaning and lubricating the eye in response to an irritation. Tearing or epiphora can be an indicator of irritation, inflammation, injury or infection of the eye. Possible causes of epiphora in pet animals are limited to allergy, physical or chemical irritants, misplaced eyelashes, eyelid growth, chemical spills, wounds or direct injury, corneal ulcer, blocked tear ducts, some systemic diseases or toxin ingestion (Menaka and Puri, 2015). In sheep, infectious keratoconjunctivitis is a contagious and economically important disease with worldwide distribution (Motha et al., 2003; Jansen et al., 2006), characterised by inflamed conjunctivae, ocular discharge, corneal opacity, and impaired vision. In severe cases, corneal ulceration and perforation can occur. As a rule, ocular le-

*Corresponding author; E-mail: katsoulo@vet.auth.gr 
sions regress spontaneously with or without treatment but relapses are common. If complications occur, lesions are slow to resolve and permanent blindness may result (Scott, 2015).

The healthy ocular surface is associated with normal tear production and a stable tear film, which have been found to be affected by several endogenous and exogenous factors, such as age, gender, the time of day and environmental conditions (Piccione et al., 2008). The Schirmer tear test (STT) is an important diagnostic tool for corneal and conjunctival disorders that measures the aqueous portion of the tear film using special paper strips (Beech et al., 2003). It remains the standard test to assess tear production in veterinary ophthalmology (Ribeiro et al., 2010). However, in order for STT to be used sufficiently in sheep practice, reference ranges should have been established. Until now, there are only limited references in the available literature reporting average STT values in certain sheep breeds (Ghaffari et al., 2011; Isler et al., 2013; Wieser et al., 2013; Akgul et al., 2017). Despite the similar recorded average values among studies, irrespectively of the breed used, the effect of breed on tear secretion has not been systematically evaluated using different sheep breeds managed under the same conditions. Moreover, the potential seasonal variation in the tear secretion of sheep has not been assessed. Such variation cannot be excluded for sheep since it has been observed in humans and horses (Beech et al., 2003; Ayaki et al., 2017).

The objective of this study was to investigate the potential effect of breed and season on STT values in sheep.

\section{Materials and methods}

Ninety ewes aged 2 to 5 years were used for study; 30 of them were of the Chios breed, 30 of the Florina (Pelagonia) breed and 30 of Lacaune mixed breed. Ewes of the Chios and Florina (Pelagonia) breeds were selected from the flock of the Research Institute of Animal Science, Hellenic Agricultural Organization, Demeter (Giannitsa, Greece; latitude: 40.79194, longitude: 22.4075) and the mixed breed ewes were selected from a flock of a commercial farm located in Lagadas region (Thessaloniki, Greece; latitude: 40.75, longitude: 23.0667). All flocks were managed identically, under an intensive system, fed a standard ration and housed in group pens with straw bedding, according to their lactation period, in semiopen sheds with multiple windows on the long-walled side.

Each flock was visited twice, on 28th of February and on 28th of August 2018. The weather conditions during these months are presented in Table 1. At each visit the animals underwent a thorough clinical examination (visual observation, rectal temperature, respiratory and heart rate evaluation, auscultation of heart, lungs and rumen, mucus membranes inspection); the eyes were especially inspected for the presence of discharge and abnormal discoloration of the con- 
junctivae. The first 15 ewes from each breed that were judged as healthy and without having any eye abnormality according to the findings of the clinical and ophthalmological examination, were selected for tear secretion evaluation at each visit. Tear secretion was measured using STT (Schirmer Strips, Eickemeyer, Germany) bilaterally by the same investigator with the animal in standing position. The strips were placed underneath the lower eyelid margin of the eye, left in place for one minute and the moistened part was measured and recorded as STT value.

\section{Table 1}

Weather conditions during February and August in the two regions where the sheep farms were located (Giannitsa and Lagadas)

\begin{tabular}{lcccccc}
\hline & \multicolumn{2}{c}{ Giannitsa $^{1}$} & & \multicolumn{2}{c}{ Lagadas $^{2}$} \\
\cline { 2 - 3 } \cline { 5 - 6 } & February & August & & February & August \\
\hline Mean temperature $\left({ }^{\circ} \mathrm{C}\right)$ & 7.8 & 26.1 & & 6.6 & 25.4 \\
Mean minimum temperature $\left({ }^{\circ} \mathrm{C}\right)$ & 4.3 & 19.9 & & 2.1 & 17.9 \\
Mean maximum temperature $\left({ }^{\circ} \mathrm{C}\right)$ & 11.9 & 33.0 & & 11.2 & 33.5 \\
Maximum temperature $\geq 32{ }^{\circ} \mathrm{C}($ number of days) & 0 & 26 & & 0 & 28 \\
Total precipitation $(\mathrm{mm})$ & 42.7 & 50.2 & & 65.8 & 34.0 \\
Number of days of rain & 17 & 6 & & 9 & 4 \\
Mean wind speed $(\mathrm{km} / \mathrm{h})$ & 3.9 & & 0.4 & & 2.4 & 0.7 \\
\hline
\end{tabular}

${ }^{1}$ Data obtained from: http://penteli.meteo.gr/stations/giannitsa/NOAAPRYR.TXT; ${ }^{2}$ Data obtained from: http://penteli.meteo.gr/stations/lagadas/NOAAPRYR.TXT

All procedures were carried out according to the ethical standards in the Helsinki Declaration of 1975, as revised in 2000, as well as the national law and the guidelines of our Institutional Animal Care and Use Committees. According to the regulations of our Institutions, a formal approval from the Ethical Committees was not required as long as STT was performed only once and is considered a typical diagnostic procedure.

The normality of the data distribution was assessed by the KolmogorovSmirnov test and the homogeneity of variances was evaluated with Levene's test. Paired samples $t$-test was used to determine the significance of the differences of STT values between the left and the right eye. Univariate ANOVA was run to evaluate the effect of season, breed and their interactions (season $\times$ breed) on the STT values. The comparison of the main effects of means was performed using Bonferroni test for the adjustment of confidence interval. All these comparisons were done at a significance level of $\mathrm{P} \leq 0.05$ using the data analysis software IBM SPSS 25. The reference interval for STT values was calculated using the statistical software MedCalc 9.2. 


\section{Results}

The range and the average values for STT values obtained in the present study, as well as those referred in the literature, are presented in Table 2 . The average STT values were not significantly different between the left and the right eye (mean \pm SE: $18.25 \pm 0.37$ and $18.83 \pm 0.41$ for the left and the right eye, respectively; $\mathrm{P}>0.05)$. The analysis revealed that tear secretion was significantly affected by season $(\mathrm{P}<0.05)$ but not by the breed of the animals or the season $\times$ breed interaction $(\mathrm{P}>0.05)$. The average STT values obtained during summer were significantly higher than those in winter (mean \pm SE: $20.08 \pm 0.66$ and $15.10 \pm 0.53$ for summer and winter, respectively; $\mathrm{P}<0.05$ ), whereas no significant difference was observed between breeds (mean \pm SE: $18.80 \pm 0.59,17.10 \pm$ 0.77 and $17.90 \pm 0.93$ for Chios, Florina and Lacaune mixed breed, respectively; $\mathrm{P}>0.05)$.

\section{Discussion}

The results obtained in the present study provide information about the reference interval for STT values in healthy ewes. Only few reports describe average STT values in domestic small ruminants (Broadwater et al., 2007; Whelan and Thompson, 2008; Ribeiro et al., 2010; Ghaffari et al., 2011; Isler et al., 2013; Wieser et al., 2013; Fornazari et al., 2016; Akgul et al., 2017) and especially in sheep (Ghaffari et al., 2011; Isler et al., 2013; Wieser et al., 2013; Akgul et al., 2017). As shown in Table 1, the average STT values reported in this study are similar to those observed in former investigations carried out in Sanjabi sheep (Ghaffari et al., 2011), Merino sheep (Isler et al., 2013) and Romanov sheep (Akgul et al., 2017) but different from those reported by Wieser et al. (2013). This difference could be possibly attributed to the different size of STT strips used in the study of Wieser et al. (2013) compared to the classic strips used in all the other ones. It is well documented that STT results can vary depending on inconsistencies in the absorptive capacity of STT strips due to differences in filter papers, the individual performing the test and the location of strip placement within the conjunctival sac (Rothschild et al., 2004).

The comparison of tear volume between the right and the left eye showed no significant differences in STT values. This finding is in agreement with those reported in other sheep (Ghaffari et al., 2011; Akgul et al., 2017) and goat studies (Broadwater et al., 2007; Fornazari et al., 2016). On the other hand, Ribeiro et al. (2010) observed that in Saanen goats the STT values were significantly different between the right and the left eye.

The results of this study prove that tear secretion is unaffected by the breed of sheep. This outcome is also confirmed by the similar average STT values documented in our report with those recorded in other studies that used different sheep breeds. 


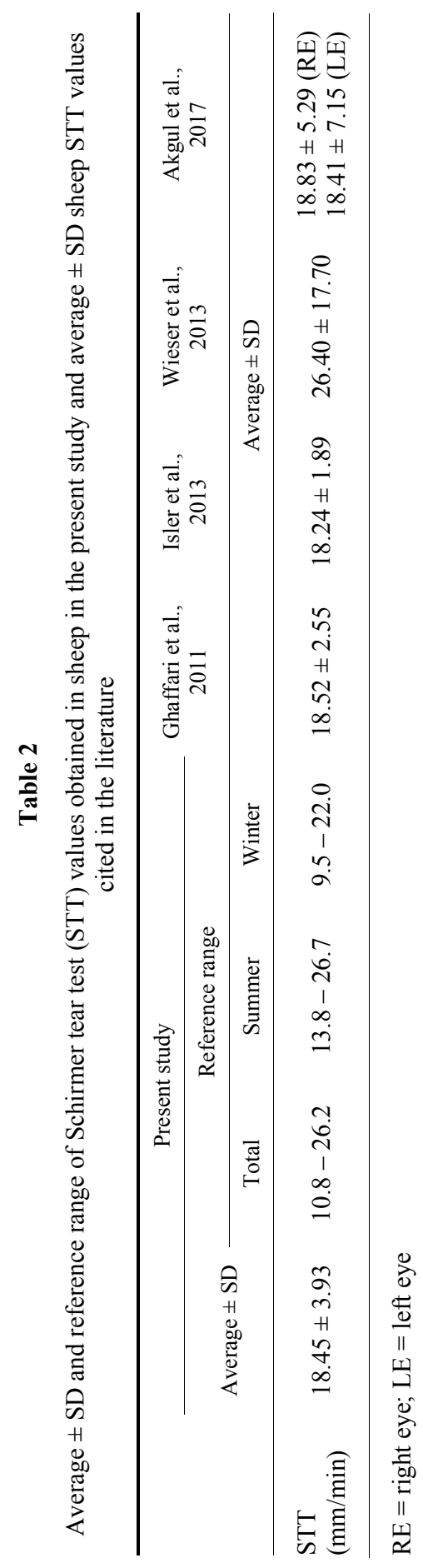


An interesting finding of the current study is the seasonal fluctuation in tear secretion in ewes, with the highest STT values being observed in summer compared to winter. No other reports currently exist regarding the effect of season on tear secretion in sheep. Previous studies in horses and ponies have demonstrated a trend for higher tear scores in STT during winter compared to the respective values in summer; however, the differences were not statistically significant (Beech et al., 2003). In accordance with our results, seasonal variation in tear production has also been observed in humans with dry eye disease, with the highest values being observed in spring and the lowest in winter (Ayaki et al., 2017). It was suggested that tear production may increase in spring as a scavenging response to an increase in seasonal allergens (Ayaki et al., 2017).

The exact mechanism for the observed variation of STT between winter and summer in this study remains unknown. A possible explanation might be that during summer there is increased irritation of the eyes due to environmental factors such as dust, insects and allergens. The very high temperatures combined with the few days of rain and the very low wind speed observed at both locations in August favour the presence of all these irritants, especially dust and insects. In addition, the ammonia concentrations are expected to be higher under these conditions contributing to increased STT values as it has been observed in Japanese black cattle (Suyama et al., 2019).

Another possible mechanism might not be related to the weather conditions but to the photoperiod and the function of the Harderian gland of the eye. One of the functions of this gland that exists in sheep is eye lubrication (Abd El Hafez et al., 2014; Rajathi et al., 2019). It has been observed in sheep that melatonin administration increases the secretion of neutral and acid mucopolysaccharides (Abd El Hafez et al., 2014). It could be hypothesised that sheep eyes are better lubricated during winter than in summer, due to the increased secretory function of the Harderian gland which is facilitated by the higher blood levels of melatonin that are naturally observed in winter compared to summer. Thus, the eye is less irritated and tears are secreted in a smaller amount. However, this hypothesis has to be further investigated.

On the other hand, seasonal changes in protein synthesis of the tear film could also affect tear production. In a comparative study, Chen et al. (2011) found a seasonal variation of camel tear fluids between summer and winter, in the composition of proteins including lactoferrin (LF) and vitelline membrane outer layer protein 1 homologue (VMO1). In previous reports, tear LF assays have been used as a predictor of tear film stability or tear volume change in the clinical practice, since decreases in LF concentration are correlated with decreases in tear production from the lacrimal gland in dry eyes (Danjo et al., 1994; McCollum et al., 1994; Da Dalt et al., 1996). Analysis of the proteomic profiles of tear fluid from human, cow, sheep and camel eyes has confirmed the presence of VMO1 protein in both camel and sheep tears (Shamsi et al., 2011). Vitelline 
membrane outer layer protein 1 homologue has been shown to interact with lysozyme C (LYSC) and have positive effects on the stabilisation of the tear film (Wang et al., 2014). However, further research is necessary to identify the causes of this difference.

In conclusion, this study provides data and reference ranges for STT values in healthy sheep. Moreover, the results of the present report indicate that there is a seasonal effect in tear secretion in sheep with higher STT scores recorded in summer than in winter, and that tear secretion is similar regardless of the breed.

\section{References}

Abd El Hafez, E. A., Abou-elhamd, A. S. and Hassan, A. H. (2014): Effects of administration of melatonin on the Harderian gland of sheep. J. Interdiscip. Histopathol. 2, 19-25.

Akgul, M. B., Sindak, N., Gulaydin, A., Ozen, D., Kahya, S. and Sulu, K. (2017): Comparative evaluations of tear secretion in healthy and infectious keratoconjunctivitis Romanov sheep with Schirmer tear test and phenol red thread tear test. Turk. J. Vet. Anim. Sci. 41, 793-797.

Ayaki, M., Kawashima, M., Uchino, M., Tsubota, K. and Negishi, K. (2017): Possible association between subtypes of dry eye disease and seasonal variation. Clin. Ophthalmol. 11, 17691775 .

Beech, J., Zappala, R. A., Smith, G. and Lindborg, S. (2003): Schirmer tear test results in normal horses and ponies: effect of age, season, environment, sex, time of day and placement of strips. Vet. Ophthalmol. 6, 251-254.

Broadwater, J. J., Schorling, J. J., Herring, I. P. and Pickett, J. P. (2007): Ophthalmic examination findings in adult pygmy goats (Capra hircus). Vet. Ophthalmol. 10, 269-273.

Chen, Z., Shamsi, F. A., Li, K., Huang, Q., Al-Rajhi, A. A., Chaudhry, I. A. and Wu, K. (2011): Comparison of camel tear proteins between summer and winter. Mol. Vis. 17, 323-331.

Da Dalt, S., Moncada, A., Priori, R., Valesini, G. and Pivetti-Pezzi, P. (1996): The lactoferrin tear test in the diagnosis of Sjogren's syndrome. Eur. J. Ophthalmol. 6, 284-286.

Danjo, Y., Lee, M., Horimoto, K. and Hamano, T. (1994): Ocular surface damage and tear lactoferrin in dry eye syndrome. Acta Ophthalmol. (Copenhagen) 72, 433-437.

Fornazari, G. A., Montiani-Ferreira, F., de Barros Filho, I. R., Somma, A. T. and Moore, B. (2016): The eye of the Barbary sheep or aoudad (Ammotragus lervia): Reference values for selected ophthalmic diagnostic tests, morphologic and biometric observations. Open Vet. J. 6, 102-113.

Ghaffari, M. S., Shojaei, M., Sabzevari, A. and Khorami, N. (2011): Reference values for intraocular pressure and Schirmer tear test in clinically normal Sanjabi sheep. Small Rumin. Res. 97, 101-103.

Isler, C. T., Altug, M. E. and Kilic, S. (2013): Evaluation of tear fluid secretion and intraocular pressure in normal merinos sheep and Saanen goats. Revue Méd. Vét. 164, 278-282.

Jansen, B. D., Heffelfinger, J. R., Noon, T. H., Krausman, P. R. and Devos, J. C. Jr. (2006): Infectious keratoconjunctivitis in bighorn sheep, Silver Bell Mountains, Arizona, USA. J. Wildl. Dis. 42, 407-411.

McCollum, C. J., Foulks, G. N., Bodner, B., Shepard, J., Daniels, K., Gross, V., Kelly, L. and Cavanagh, H. D. (1994): Rapid assay of lactoferrin in keratoconjunctivitis sicca. Cornea 13, 505-508.

Menaka, R. and Puri, G. (2015): Role of lacrimal gland in tear production in different animal species: A review. Livest. Res. Int. 3, 40-42. 
Motha, M. X., Frey, J., Hansen, M. F., Jamaludin, R. and Tham, K. M. (2003): Detection of Mycoplasma conjunctivae in sheep affected with conjunctivitis and infectious keratoconjunctivitis. N. Z. Vet. J. 51, 186-190.

Ohashi, Y., Dogru, M. and Tsubota, K. (2006): Laboratory findings in tear fluid analysis. Clin. Chim. Acta 369, 17-28.

Piccione, G., Giannetto, C., Fazio, F. and Giudice, E. (2008): Daily rhythm of tear production in normal horse. Vet. Ophthalmol. 11 (Suppl. 1), 57-60.

Rajathi, S., Ramesh, G., Raja, K., Kannan, T. A., Sriram, P. and Hemalatha, S. (2019): Microscopic anatomy of Harderian gland in goats. J. Entomol. Zool. Stud. 7, 1413-1418.

Ribeiro, A. P., Piso, D. Y. T., Padua, I. R. M., Silva, M. L. and Laus, J. L. (2010): Intraocular pressure and tear secretion in Saanen goats with different ages. Pesq. Vet. Bras. 30, 798-802.

Rothschild, C. M., Sellon, D. C., Bryan, G. M., Gay, J. M. and Hines, M. T. (2004): Effects of trimethoprim-sulfadiazine on tear production and the fluctuations of Schirmer tear test values in horses. Vet. Ophthalmol. 7, 385-390.

Scott, P. (2015): Sheep Medicine. Second edition. CRC Press, New York. 448 pp.

Shamsi, F. A., Chen, Z., Liang, J., Li, K., Al-Rajhi, A. A., Chaudhry, I. A., Li, M. and Wu, K. (2011): Analysis and comparison of proteomic profiles of tear fluid from human, cow, sheep, and camel eyes. Invest. Ophthalmol. Vis. Sci. 52, 9156-9165.

Suyama, Y., Matsuda, K., Teshima, T., Matsumoto, H. and Koyama, H. (2019): The effect of environmental and biological factors on STT I and normal total tear protein concentration in Japanese black calves. J. Vet. Med. Sci. 81, 26-29.

Tiffany, J. M. (2008): The normal tear film. Dev. Ophthalmol. 41, 1-20.

Wang, Z., Chen, Z., Yang, Q., Jiang, Y., Lin, L., Liu, X. and Wu, K. (2014): Vitelline membrane outer layer 1 homolog interacts with lysozyme $C$ and promotes the stabilization of tear film. Invest. Ophthalmol. Vis. Sci. 55, 6722-6727.

Whelan, N. C. and Thompson, D. (2008): Normal ophthalmic diagnostic test values in Angora goats [Abstract]. 39th Annual Meeting of the American College of Veterinarian Ophthalmologists, Boston, MA, USA. Vet. Ophthalmol. 11, 419.

Wieser, B., Tichy, A. and Nell, B. (2013): Correlation between corneal sensitivity and quantity of reflex tearing in cows, horses, goats, sheep, dogs, cats, rabbits, and guinea pigs. Vet. Ophthalmol. 16, 251-262. 